\title{
midiäticale
}

\section{As Histórias em Quadrinhos e suas autoras: uma introdução}

\author{
Women in comics: an introductory guide
}

\author{
Alberto Ricardo PESSOA ${ }^{1}$
}

\section{Resumo}

$\mathrm{O}$ artigo disserta acerca do quadrinho autoral feminino a partir de uma cartografia em torno de suas principais autoras, desde os primórdios com Rose O'Neill até o contemporâneo com Marjane Satrapi. A análise busca afirmar que as mulheres foram tão pioneiras quanto os homens nas representações gráficas sequenciais, criaram Super heroínas que foram contraponto do Mainstream dos Comics americano, desenvolveram um gênero próprio dentro do Mangá Japonês e participaram em antologias de quadrinhos consagradas na América e na Europa com uma maneira peculiar de construção imaginária do humor e seu reflexo no cotidiano da sociedade. A nossa hipótese é que os quadrinhos autorais femininos apontam um discurso humorístico em comum com traços ingênuos, grotescos, personagens autobiográficos e com novas construções de imaginário que refletem o cotidiano de seus leitores. Apresentamos uma introdução às autoras, publicações, editoras e ao legado delas nas Histórias em Quadrinhos.

Palavras-Chave: Autoralidade. Histórias em Quadrinhos. Feminino.

\begin{abstract}
The article discusses the female comic book from a cartography around its main authors, from the beginnings with Rose O'Neill to the contemporary with Marjane Satrapi. The analysis seeks to state that women were as pioneers as men in sequential graphic representations, created Super Heroines that were counterpoint to the American Comics Mainstream, developed a genre of their own within the Japanese Manga and participated in consecrated comic anthologies in America and Europe with a peculiar way of imaginary construction of humor and its reflection in the daily life of society. Our hypothesis is that female comic books point to a humorous discourse in common with naïve, grotesque traits, autobiographical characters and new imaginary constructions that reflect in the daily life of their readers. We present an introduction to the authors, publications, publishers and their legacy in comic books.
\end{abstract}

Key-Words: Authorality. Comics. Female.

\footnotetext{
${ }^{1}$ Pós-doutor em Sociologia. Professor do Programa de Pós-Graduação em Comunicação (PPGC/UFPB) e de Comunicação em Mídias Digitais (DEMID/UFPB). E-mail: albertoricardopessoa@gmail.com
}

Ano XI, n. 21 - jul-dez/2018 - ISSN 1983-5930 - http://periodicos.ufpb.br/ojs2/index.php/cm 


\section{midiätica@e}

\section{Introdução}

No final do século XIX, as Histórias em Quadrinhos começaram simultâneamente em diversos países, como uma categoria das caricaturas, charges, cartuns e histórias ilustradas. A concepção de pequenos quadros sequenciais em uma página ilustrada com texto verbal e sendo complementada por um discurso não verbal, logo encontrou no conectivo balão de texto uma forma de leitura autônoma e diferente do que os leitores já haviam visto no que se refere ao ato de contar histórias.

Desde seus primórdios as Histórias em Quadrinhos foram muito bem recebidas, principalmente pelo público infanto juvenil. Isso se deve pela viabilização de publicação dos quadrinhos que sempre teve acolhida nos veículos de comunicação de massa, como os jornais.

Naturalmente, os pioneiros dessa linguagem sequencial gráfica foram escritores e artistas gráficos que tinham trânsito na imprensa de seus respectivos países. Ângelo Agostini (1843 - 1910), Rodolphe Töpffer (1799 - 1846), Richard Felton Outcault (1863 - 1928) criaram histórias, personagens e as bases do que conhecemos como Histórias em Quadrinhos.

De acordo com Thierry Groensteen (2015, p.17).

Töpffer viu no texto e na imagem dois componentes equivalentes dos quadrinhos, que ele define a partir do seu caráter misto. Esse ponto de vista ainda era sustentável na sua época, mas hoje não mais. De fato, aqueles que atribuíram ao verbal um status igualitário ao status da imagem na economia dos quadrinhos partem do princípio de que a escrita é o veículo privilegiado da narração em geral. No entanto, a multiplicidade de espécies narrativas tornou esta suposição obsoleta.

Nas Histórias em Quadrinhos havia personagens em diversos contextos sociais, como o caipira Nhô Quim ou o imigrante chinês em The Yellow Kid. No que se refere aos autores de Histórias em Quadrinhos o cenário era predominantemente masculino. Contexto que até hoje se mantém, principalmente quando o foco de análise se atém aos quadrinhos massificados.

Escritores, desenhistas, arte-finalistas e coloristas são em sua grande maioria homens, e os historiógrafos não esclarecem em suas pesquisas a participação das mulheres nas Histórias em Quadrinhos; muitos as colocam numa condição de 


\section{midiäticale}

coadjuvante ou, ainda, propõem que se trata de uma participação contemporânea de uma nova geração de artistas.

A dificuldade em encontrar pesquisas que inserem as mulheres na construção das Histórias em Quadrinhos como discurso, linguagem e forma de expressão justifica a importância que o referido artigo se propõe.

A partir deste escopo, pretendemos apresentar uma breve introdução de natureza exploratória com o intuito de levantar uma cartografia de autoras de Histórias em Quadrinhos e assim entender o contexto dessas autoras nos principais ciclos de criação e produção das Histórias em Quadrinhos ao longo do século XX e início do Século XIX. Este artigo pretende ser o primeiro de uma série de estudos acerca do tema, do qual finda com a compreensão do discurso autoral das mulheres nos quadrinhos.

\section{Primórdios das Histórias em Quadrinhos}

As mulheres encontraram no universo das Histórias em Quadrinhos diversas dificuldades de inserção, como a necessidade de abster de seus nomes como autoras e trocar por pseudônimos, produzir material de direcionamento heteronormativo ou para uma formação estereotipada da mulher dona de casa, casada e uma predominância de personagens e histórias voltadas para o público masculino.

Esse fator faz com que os dados acerca das pioneiras das Histórias em Quadrinhos sejam difusos e até mesmo controversos, como podemos verificar ao considerarmos a produção de mais de um século de Histórias em Quadrinhos e os poucos nomes de autoras em publicações, premiações e, inclusive, em pesquisas históricas, entendemos que há falta de publicização da representatividade feminina histórica nos quadrinhos; e pela escassez de pesquisa, este artigo se coloca como uma introdução ao tema.

Nos primórdios da imprensa e com o advento de novos processos gráficos de impressão como a litogravura, as iluminuras começaram a fazer parte de artigos, notícias e histórias. As Ilustradoras se destacaram ao aplicar a estética nouveau em seus trabalhos. Eram artistas com uma condição excepcional: tinham créditos nos seus trabalhos e eram devidamente remuneradas. Migrar para uma linguagem que buscava se firmar como os quadrinhos era para artistas entusiastas com a nova linguagem ou quem ainda não tinha um nome no mercado. De acordo com Trina Robbins (2018, p. 03): 


\section{midiätica@e}

Nos anos 20, os jornais apresentavam flappers desenhados por mulheres em um estilo Art Deco simplificado. As mulheres tinham o voto, e a nova estrela das revistas em quadrinhos dos Estados Unidos bebia e fumava, usava saias curtas e brincava com os garotos. O mais prolífico e bem-sucedido desse novo grupo de cartunistas foi Ethel Hayes, cujo trabalho foi influenciado tanto por Brinkley quanto pelo famoso cartunista John Held Jr., de 1920. Hayes produziu um prodigioso corpo de trabalho nos anos 20 e 30. Junto com livros infantis e livros de bonecas de papel, ela conseguiu publicar uma folha de jornal de domingo, uma faixa em preto e branco intitulada "Marianne", e dois painéis diários, Flapper Fanny e Ethel, com seus comentários em arte. a maneira de Nell Brinkley. Outro cartunista melindroso era a igualmente prolífica Virginia Huget, que com uma colorida página de domingo e pelo menos duas tiras diárias, todas exibindo flappers inspiradas na estrela do cinema mudo Louise Brooks, também encontraram tempo para desenhar anúncios de sabonetes Lux ${ }^{2}$. (Tradução nossa)

Assim, uma das pioneiras das Histórias em Quadrinhos, não só entre mulheres, mas entre os criadores é Rose O'Neill.

Figura 01

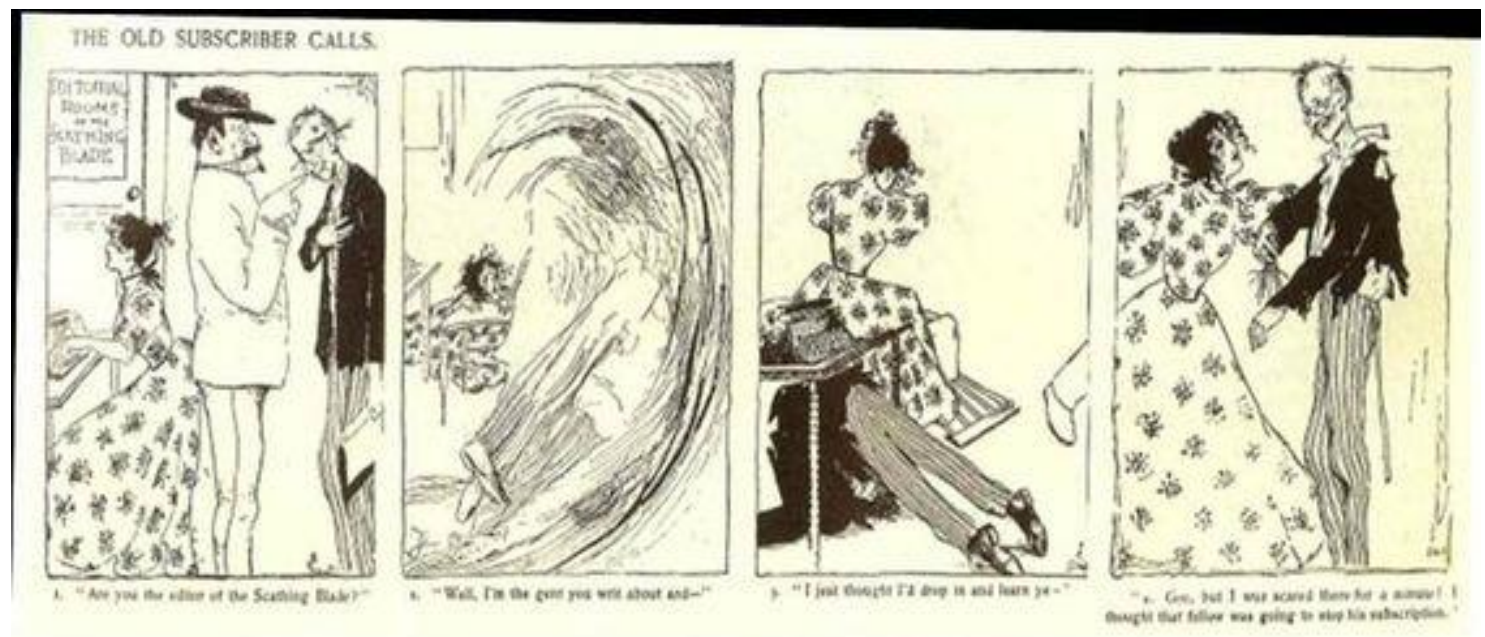

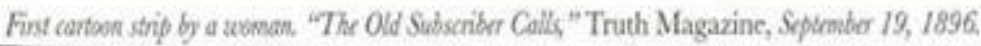

Fonte: O’Neill (2018)

\footnotetext{
${ }^{2}$ By the twenties, newspapers featured flappers drawn by women in a streamlined, Art Deco style. Women had the vote, and the new star of America' s comics pages drank and smoked, wore short skirts, and wisecracked with the boys. The most prolific and successful of this new group of cartoonists was Ethel Hayes, whose work was influenced by both Brinkley and by famous 1920s cartoonist John Held, Jr. Hayes produced a NACAE National Association of Comics Art Educators This document is free for noncommercial educational use. See http://www.teachingcomics.org/copy.php for complete copyright information. prodigious body of work throughout the twenties and thirties. Along with children' s books and paperdoll books, she managed to turn out a full page Sunday newspaper strip, a black and white strip titled "Marianne," and two daily panels, Flapper Fanny, and Ethel, with her commentary running under the art, in the manner of Nell Brinkley. Another flapper cartoonist was the equally prolific Virginia Huget, who, with a full color Sunday page and at least two daily strips, all featuring flappers modeled after silent film star Louise Brooks, also found the time to draw ads for Lux soap.
}

Ano XI, n. 21 - jul-dez/2018 - ISSN 1983-5930 - http://periodicos.ufpb.br/ojs2/index.php/cm 


\section{midiätica@e}

A artista começou a produzir Histórias em Quadrinhos em 1901 e criou uma série conhecida como Immortal Kewpies que fez bastante sucesso entre o seu público alvo, que foi, na sua grande maioria, crianças. Importante destacar que O’Neill não foi uma artista de exceção no universo das Histórias em Quadrinhos. Segundo Trina Robbins (2018, p.02):

O'Neill, que ficaria famoso como o criador dos immortal Kewpies, não ficou sozinho por muito tempo. Em 1901, uma história em quadrinhos de Louise Quarles, "Bun's Pus", foi veiculada no New York Herald e, um ano depois, os jornais publicaram tiras de Jean Mohr, Kate Carew e Grace Gebbie Weidersheim. Esta última, sob o nome de casada de Grace Drayton, é mais conhecida por criar as crianças Campbell em 1905. Até sua morte em 1936, Drayton produziu inúmeras Histórias em Quadrinhos com crianças lindas, todas parecidas com as Campbell Kids, com uma confusão de nomes como Toodles. Dolly Drake, Bobby Blake, Dolly Dingle, Dolly Dimples e Dotty Darling. Os primeiros cartunistas como Drayton e Rose O'Neill foram extremamente prolíficos, publicando em revistas como The Ladie Home Journal, Woman's Man Companion e Good Housekeeping, bem como jornais nacionais ${ }^{3}$. (Tradução nossa).

A linha de humor ingênuo de cunho educacional se assemelha ao trabalho de Rudolphe Töpffer e se afasta da crítica social impregnada em quadrinhos como de Ângelo Agostini ou Richard Outcault. A quadrinista é uma das poucas artistas a trabalhar com uma série regular de quadrinhos e assinar como autora. A maioria assinava com pseudônimos masculinos no intuito de evitar o machismo e preconceito da época.

Com o surgimento das revistas em quadrinhos e o sucesso comercial em torno de Superman de Jerry Siegel e Joe Shuster em 1938, houve uma profusão de personagens dotados de superpoderes e com diversos estereótipos heteronormativos. A criação de Super-heróis era predominantemente masculina, com autores como Stan Lee, Steve Ditko, Jack Kirby, entre outros.

\footnotetext{
${ }^{3} \mathrm{O}^{\prime}$ Neill, who would become famous as the creator of the immortal Kewpies, wasn' $t$ alone for long. By 1901, a comic by Louise Quarles, "Bun' s Pnus", ran in the New York Herald, and a year later, newspapers carried strips by Jean Mohr, Kate Carew and Grace Gebbie Weidersheim. The latter, under her married name of Grace Drayton, is best known for creating the Campbell Kids in 1905. Until her death in 1936, Drayton produced countless comics featuring cute toddlers, all looking like the Campbell Kids, with a confusion of names like Toodles, Toddles, Dolly Drake, Bobby Blake, Dolly Dingle, Dolly Dimples, and Dotty Darling. Early cartoonists like Drayton and Rose O' Neill were extremely prolific, publishing in magazines like The Ladies' Home Journal, Woman' s Home Companion, and Good Housekeeping, as well as national newspapers.
}

Ano XI, n. 21 - jul-dez/2018 - ISSN 1983-5930 - http://periodicos.ufpb.br/ojs2/index.php/cm 


\title{
midiäticales
}

Em 1941 June Mills criou, escreveu e desenhou a Miss Fury. Ela foi publicada como revista própria na Timely Comics e trata de uma heroína publicada nos primórdios dos quadrinhos considerados pulps, ou seja, de detetives, e conta a história de uma personagem independente e forte o suficiente para atuar em suas missões como protagonista.

É importante frisar que Miss Fury surgiu numa época em que a maioria das personagens femininas eram caracterizadas como coadjuvantes, frágeis, vítimas ou mulheres fatais que usam da sensualidade para conseguir seus objetivos. Na trama ela é Marla Drake, uma socialite que ao vestir uma manta de Pantera vai às ruas combater o crime.

Miss Fury se posicionou no imaginário do leitor como uma heroína na acepção do termo e com um senso de humor típico dos super-heróis, mas com o protagonismo feminino. Segundo Laurenn McCubbin (2018, p.01):

\begin{abstract}
"Na primeira metade do século XX, muitas cartunistas femininas escreviam sob nomes ambíguos ou masculinos, apenas para aumentar sua aparência de publicação". McGurk tem muitos exemplos: June Mills, que usou uma versão de seu nome do meio, "Tarpé", quando ela criou a grande Miss Fury em 1941. Miss Fury, na verdade, foi a primeira heroína de ação feminina criada por uma mulher, antes da Wonder Woman ${ }^{4}$. (Tradução nossa)
\end{abstract}

Infelizmente foi uma criação de exceção. No cenário considerado Mainstream de quadrinhos as mulheres tinham pouco espaço de inserção, seja como autoras, escritoras, desenhistas ou editoras. $\mathrm{O}$ universo dos quadrinhos mainstream é predominantemente masculino.

No Brasil temos como hipótese que a pioneira nas Histórias em Quadrinhos seja a Jornalista Helena Ferraz com o personagem o Garra Cinzenta, publicado na Gazetinha entre 1937 e 1939. Segundo Worney de Almeida Souza (2011, p.08).

(...) O primeiro capítulo saiu na edição de número 235 , de 27 de julho de 1937. E com um mistério adicional: ninguém sabe com certeza quem seria Francisco Armond. Todos os indícios sugerem que fosse a

\footnotetext{
${ }^{4}$ For the first half of the 20th century, many female cartoonists wrote under ambiguous or masculine names, just to increase their likeliness for publication. McGurk has many examples: June Mills, who went by a version of her middle name, "Tarpé", when she created the great Miss Fury in 1941. Miss Fury, in fact, was the first female action hero created by a woman, predating Wonder Woman.
} 


\section{midiäticales}

jornalista Helena Ferraz, mas ela nunca assumiu a autoria publicamente.

Outra artista que teve uma produção regular nas Histórias em Quadrinhos, além de charge e cartoon, gêneros que dialogam com os quadrinhos, foi Hilde Weber, que entre seus trabalhos publicados na Tribuna da Imprensa na década de 1950 podemos destacar seu engajamento político.

Como podemos perceber, nos primórdios das Histórias em Quadrinhos temos autoras que surgiram e se colocaram como autoras regulares de seus respectivos trabalhos. Esse pioneirismo no entanto mostrou-se pouco para as mulheres e é somente na contracultura que o cenário das autoras de quadrinhos começa a se multiplicar.

\section{Contracultura e influências das autoras de Histórias em Quadrinhos}

Os autores de Histórias em Quadrinhos foram criadores que ao longo do tempo souberam se adaptar aos avanços tecnológicos, bem como escrever histórias, personagens e discorrer acerca de assuntos contemporâneos à sociedade. A contracultura trouxe publicações independentes e comercializadas pelos próprios autores. Assim, a produção de Histórias em Quadrinhos em pequenos meios, com a comercialização fora do contexto de grandes editoras, jornais ou sindicatos fez com que novos autores surgissem com propostas ousadas comparado com o quadrinho comercial.

Segundo Dan Mazur e Alexander Danner (2014, p.23)

Em 25 de fevereiro de 1968, Robert Crumb e Dana, sua mulher na época, começaram a vender exemplares de Zap Comix n.1 num carrinho de bebê pelas ruas de Haight Ashbury, em São Francisco. A alegre coleção de poucas páginas dos quadrinhos escandalosamente sem censura de Crumb foi um sucesso instantâneo entre moradores, hippies pós-Verão do Amor. Começava o Movimento Underground dos quadrinhos Norte-Americanos.

Escritoras, artistas e entusiastas passaram a criar conteúdo para Histórias em Quadrinhos e compartilhar em antologias e revistas. O fenômeno foi global e presente em diversos gêneros das Histórias em Quadrinhos.

Nas Histórias em Quadrinhos norte-americanas publicadas de maneira independente, podemos observar o surgimento de autoras que se afastaram do mundo dos Super-Heróis e passaram a escrever com base em seu imaginário criativo, histórias 


\section{midiäticales}

acerca do próprio cotidiano, com o humor ácido e estilo calcado nos cartoons, que privilegia a distorção da forma para exagerar nos efeitos dramáticos da mensagem.

Segundo Dan Mazur e Alexander Danner (2014, p. 30),

No caso das mulheres, o movimento underground apresentou oportunidades, mas também frustrações. A artista Trina Robbins, uma das poucas mulheres artistas em atividade nos primórdios do underground, começou a desenhar quadrinhos para promover sua loja de roupas em East Village; em seguida, mudou-se para São Francisco, e seus desenhos chegaram a antologias como Yellow Dog. Suas histórias combinavam o glamour dos anos 1940 com heroínas de ação - aventuras carinhosamente satíricas com mensagens feministas.

Podemos observar a diferença de temas e preocupações sociais quando comparamos uma história em quadrinhos comercial de uma independente da época. Enquanto Batman era caracterizado para se tornar um personagem infantilizado, com aventuras pueris, Aline Crumb focou em criar uma versão em quadrinhos de si mesma, tratando de temas como sexo, drogas, a sociedade da época, dentre outros assuntos que eram considerados impossíveis de se ver nas Histórias em Quadrinhos comerciais.

Além dos temas, a própria estética adotada pelas autoras era fora dos padrões de qualidade das Histórias em Quadrinhos comerciais. Em São Francisco, local de efervescência criativa das Histórias em Quadrinhos independentes, as autoras foram primordiais no que consideramos um divisor no que se refere a autoralidade nas Histórias em Quadrinhos em escala global. Segundo Dan Mazur e Alexander Danner (2014, p.20)

\footnotetext{
(...) o movimento dos quadrinhos underground teve seu apogeu basicamente entre o final da década de 1960 e meados de 1970, a influência tanto de obras como de autores ampliou-se bem além das fronteiras do estado da Califórnia e atingiu os países europeus e latinoamericanos, podendo-se afirmar que ajudaram na formulação de um estilo de produção de quadrinhos. Na Europa eles foram fontes de inspiração para revistas de vanguarda. Nas américas, por sua vez, assumiram forte viés político- partidário, sendo o estilo preferencial utilizado por artistas latino-americanos para o enfrentamento de governos autoritários que se espalharam pelo continente nas décadas de 1960 e 1970.
}

Um dos exemplos foram as Histórias em Quadrinhos italianas, o Fumetto, que possui uma das estruturas mais tradicionais, tanto na linguagem gráfica quanto no texto; criou um dos anti-heróis mais interessantes do universo das Histórias em Quadrinhos. 


\section{midiătica@ \\ REVISTA DO PROGRAMADE \\ PÓS-GRADUAÇÃO EM COMUNICAÇÃO DA \\ UNIVERSIDADE FEDERAL DA PARAIBA}

Figura 02

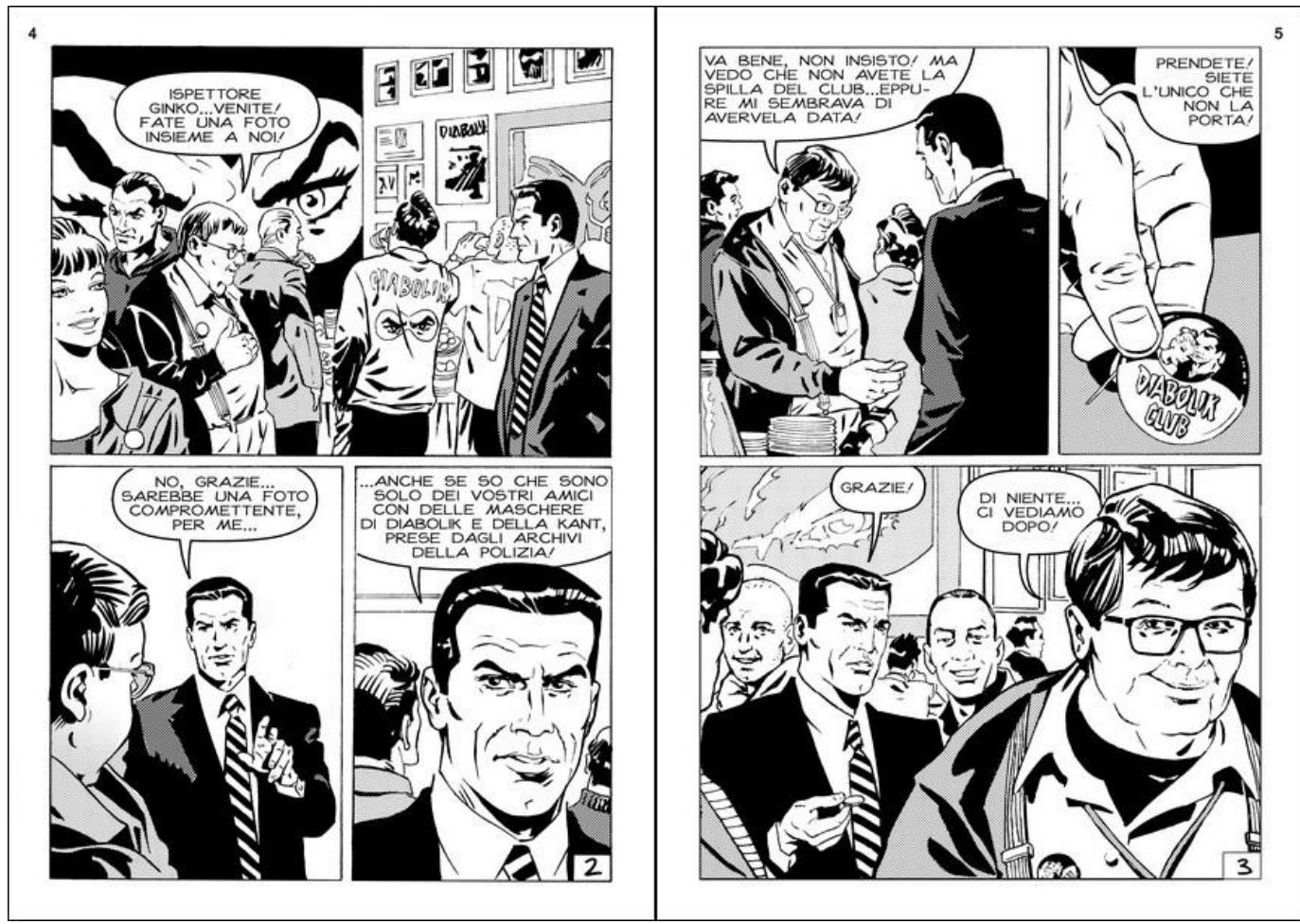

Fonte: Giussani (2018)

Trata-se de um gênio do crime, que ao lado de sua esposa executa os mais diversos roubos e aventuras burlescas para o tormento dos personagens coadjuvantes, na sua maioria policiais e vítimas do antagonista. De acordo com Dan Mazur e Alexander Danner (2014, p.17).

Na itália, um novo gênero de quadrinhos dark, violento e erótico, do gênero policial, refletia a nova liberdade cultural e afrouxamento da moral da Igreja Católica. Os chamados fumetti neri (quadrinhos negros) tinham entre os principais títulos Diabolik, criado pelas irmãs Angela e Luciana Giussani.

A série Diabolik é uma das poucas séries criadas por autoras que continua a ser produzida de forma ininterrupta até hoje. O gênero Noir é predominante na série e possui um contraponto interessante em relação ao personagem mais famoso das Histórias em Quadrinhos italianas, que é Tex, um ranger que defende a honra, justiça e valores de uma sociedade tradicional e conservadora. 


\section{midiätica@e}

A emancipação feminina na história em quadrinhos japonesa, o Mangá, se deu por meio de um gênero criado especificamente para o público feminino, o Shoujo Mangá. O gênero, criado por Osamu Tesuka, tinha como premissa uma série de histórias calcadas em romance e uma construção do imaginário feminino a partir de autores masculinos. De acordo com Dan Mazur e Alexander Danner analisa (2014, p.14)

(...) as mulheres mais jovens estavam escrevendo e desenhando mangá, o mangá shoujo refletia cada vez mais a realidade contemporânea de uma forma que iria atrair as adolescentes japonesas. Mary Lou, de Yoshiko Nishitani (1965), é considerado o primeiro mangá shoujo a focar romance adolescente contemporâneo.

A partir do ponto que artistas passaram de assistentes para autoras, novas percepções e discussões acerca de temáticas femininas passaram a fazer parte do Shoujo Mangá. Dentro de uma sociedade fechada como a japonesa, o Shoujo Mangá passa a ser um meio de comunicação importante para a mulher, uma vez que o mangá é bastante popular naquela sociedade e folheado por crianças, adolescentes e adultos. Segundo Dan Mazur e Alexander Danner (2014, p.68)

(...) Em 1965, Mary Lou, de Yoshiko Nishitani, foi considerado o primeiro mangá Shoujo a retratar os problemas românticos das adolescentes japonesas contemporâneas: namorados, encontros, baile de formatura etc. Em 1969, Fire [Fogo], de Hideko Mizuno, mostrou cenas de sexo reais, praticamente explícitas; em 1970, Yumiko Oshima publicou Tanjou [Nascimento], a história de uma adolescente solteira que engravida e lida com a questão do aborto; no ano seguinte, 1971, O colegial em novembro, de Moto Hagio, e Shiroi Heya no Futari, de Ryoko Yamagishi, retrataram a homossexualidade (masculina e feminina, respectivamente) entre adolescentes em internatos.

Outro núcleo importante de criação e produção de quadrinhos por mulheres foi a França com algumas antologias importantes como a publicação Ah! Nana! que reuniu as principais colaboradoras da Europa e América. Outra Antologia muito importante para o desenvolvimento dessas autoras foi a Mètal Hurlant que, diferente das antologias citadas até então conseguiu estabelecer um equilíbrio entre homens e mulheres no que se refere a publicação autoral. A Mètal Hurlant era uma revista mais calcada na fantasia e ficção científica do que política, cerne da antologia Ah! Nana!, mas soube respeitar os posicionamentos das autoras e publicar seus trabalhos na íntegra.

Ano XI, n. 21 - jul-dez/2018 - ISSN 1983-5930 - http://periodicos.ufpb.br/ojs2/index.php/cm 


\title{
midiätica@e
}

No Brasil o movimento de contracultura foi essencial para o surgimento de uma das autoras mais produtivas e interessantes que citamos nesse referido artigo. Conceição Cahú foi cartunista e autora de Histórias em Quadrinhos com produção publicada principalmente em Jornais como a Folha de São Paulo, Jornal da Tarde, Gazeta Mercantil e Diário do Comércio Indústria \& Serviços.

A artista é uma das poucas quadrinistas que conseguiu publicar trabalhos com discursos feministas em publicações comerciais como jornais. Sua produção que permeou 04 (quatro) décadas de produção, foi contemplada com o prêmio de melhor quadrinho no Salão de Piracicaba em 1992. É a representante mais importante dos quadrinhos pré internet, uma vez que se na contracultura temos um aumento substancial de autoras, é com o advento da internet e da cultura de conexão que de fato as autoras encontram um espaço de expressão jamais visto anteriormente.

\section{Autoras contemporâneas de Histórias em Quadrinhos}

Nos últimos anos, ações importantes no que se refere à publicação, organização de grupos criativos e criadores que optaram por tornar os quadrinhos sua principal via de expressão fizeram com que os quadrinhos autorais femininos encontrassem uma franca expansão e ampliasse o leque de opções para o leitor regular de Histórias em Quadrinhos.

De acordo com Thierry Groensteen (2015, p.17)

\begin{abstract}
A evolução estética da história em quadrinhos, passado um quarto de século, se deu no sentido de uma libertação da imagem. O desenho narrativo tradicional, tal como o que prevalece desde Töpffer até Franquin e de Milton Caniff até Mézières, se viu em concorrência com mãos mais soltas mais pictóricas, mais poéticas. (...) a história em quadrinhos mostrou que pode aceitar o desenho ilustrativo, e que pode inclusive abandonar por completo o desenho linear, em benefício do jogo livre de superfícies e cores, de luzes e intensidades.
\end{abstract}

A cultura de conexão com redes sociais propiciaram autoras a se libertarem de convenções impostas por editoras, fazendo com que passassem a publicar o próprio material na internet. Um dado dessa ação é que se quanto ao formato impresso as mulheres tiveram poucos trabalhos premiados ou lembrados em eventos de quadrinhos, o mesmo não se perfaz no âmbito das publicações na WEB, onde incluímos categorias como melhor quadrinho publicado. 


\section{midiătica@ \\ REVISTA DO PROGRAMA DE

Figura 3

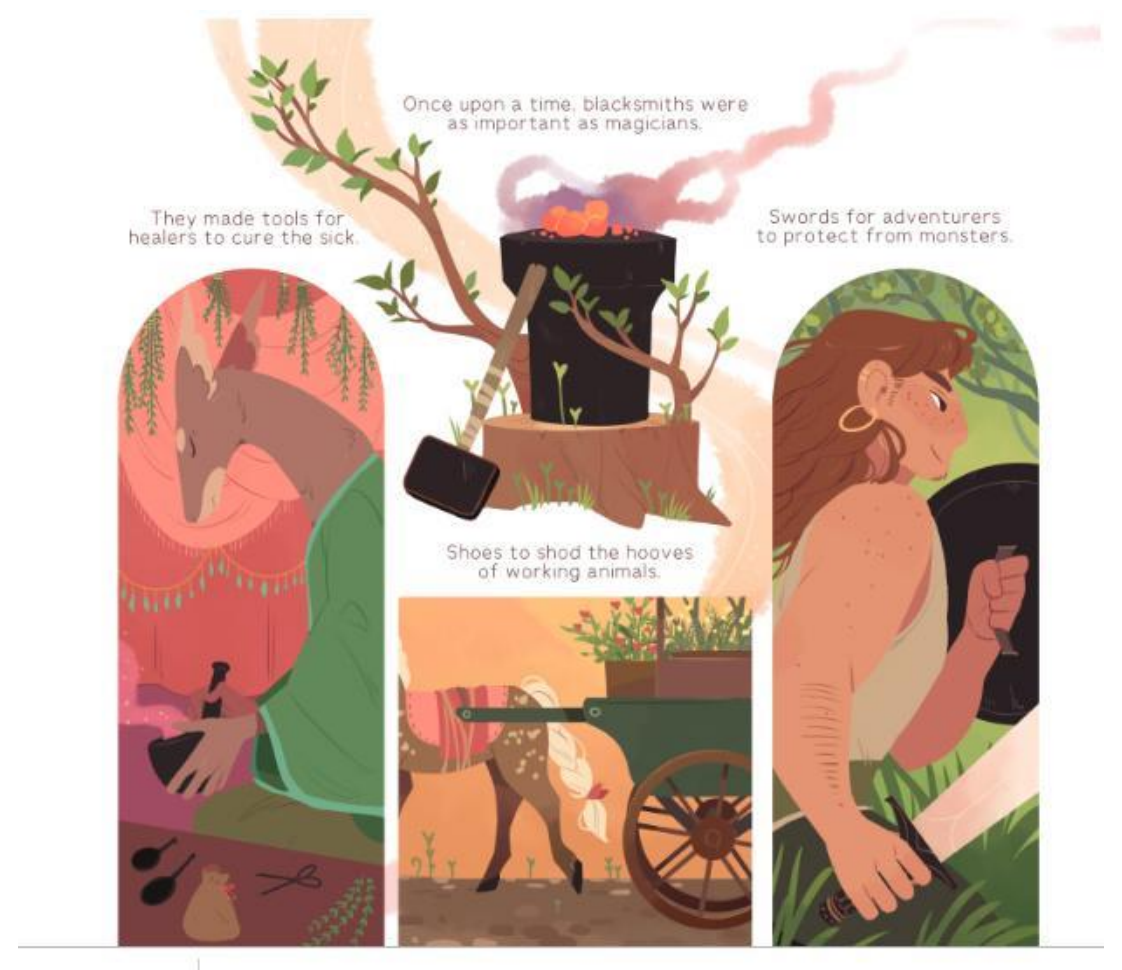

Fonte: (O’Neill, 2018)

Um exemplo é da artista Katie O’Neill, a história em quadrinhos via web The Tea Dragon Society, premiado como melhor webcomics de 2018 no Eisner Awards.

De acordo com Henry Jenkins (2014, p.290):

(...) os webcomics (quadrinhos via web) prosperam em comunidades muito diferentes e as pessoas criam material de Histórias em Quadrinhos por razões muito diferentes. Algumas estão tentando aprimorar suas habilidades, demonstrar potencial de mercado ou construir uma reputação antes de se tornar profissionais. Elas podem passar para a impressão ao encontrarem seu nicho. Outras ainda optam por permanecer no meio digital, apesar de ofertas de editores que trabalham com impressão.

O gênero autobiografia acolheu as autoras e vice-versa. forma visceral de contar a própria história de vida das autoras como Alison Bechdel fez sucesso a tal ponto que a sua história em quadrinhos como Fun Home, de 2006 foi adaptada para o teatro e musical da Broadway. Outro caso é o de Majane Satrapi, com Persépolis de 2000 que foi adaptado para animação e indicado ao Oscar em 2007.

De acordo com Valdomiro Wergueiro (2009, p.35), 


\section{midiätica@e}

(...) outro gênero que adquire força nesse novo momento de legitimação das Histórias em Quadrinhos é a narrativa pessoal, enfocando relatos de vida e memórias. É um gênero que tem suas raízes nos quadrinhos underground, principalmente com o trabalho de Robert Crumb, e que posteriormente, com seus sucessores no âmbito do hoje denominado quadrinho alternativo, atingiu níveis de qualidade antes pouco vislumbrados, mesmo pelos admiradores do gênero.

De todos os gêneros das Histórias em Quadrinhos, podemos afirmar a partir da análise de Laureen McCubbin que no Mangá as profissionais conseguiram um equilíbrio entre autoralidade, sucesso comercial e produção. Coletivos de artistas, franquias de personagens, convergência de seus trabalhos em outras mídias e um pensamento de produção para cultura de massa é algo que não vemos entre autoras de Histórias em Quadrinhos, comics ou fumetto. De acordo com McCubbin (2018, p.01 tradução nossa),

Há as mulheres do coletivo de mangá japonês Clamp, cujo trabalho vai desde o mítico shojo (mangá de garotas) RG Veda ao mangá seinen (mangá de homens adultos) Chobits. Sua produção supera todos, mas o mais prolífico dos criadores, com sua influência vista em quadrinhos e desenhos animados em todo o mundo.

No Brasil podemos destacar artistas como Lu Caffagi, Bianca Pinheiro e Fabiane Langona que vêm sendo publicadas com regularidade, seja por editoras ou por iniciativas como financiamento coletivo, o que faz com que o cenário de quadrinistas mulheres seja uma realidade hoje no país e não uma cultura de exceção.

É importante frisar que ainda há muitos casos de preconceito com as autoras de Histórias em Quadrinhos. Quando consideramos os quadrinhos comerciais, o público consumidor ainda é predominantemente masculino. Por fim, os próprios críticos de Histórias em Quadrinhos produzem um conteúdo preconceituoso, como podemos ver na afirmação de Franck Bondoux, apresentado por McCubbin (2018, p.01 tradução nossa)

Para piorar a situação, em uma entrevista notavelmente equivocada, o diretor executivo do festival, Franck Bondoux. (...) "O Festival gosta de mulheres, mas não pode reescrever a história dos quadrinhos", disse ele. Bondoux citou a história da arte como suporte. "Se você for ao Louvre", ele disse, "você encontrará poucas mulheres artistas".

Felizmente, pesquisadores, autores, críticos, entusiastas e fãs da arte sequencial estão lutando pela reversão deste cenário, seja por meio de boicotes à festivais que não 


\section{midiäticale}

indicam mulheres nas premiações, seja por pedidos de escritoras e artistas em títulos de super-heróis e por publicações de novos trabalhos de autoras. Acreditamos que a própria busca por novos conteúdos irá fazer com que as mulheres consigam equilibrar nos próximos anos a criação, produção e compartilhamento de Histórias em Quadrinhos.

\section{Considerações finais}

A premissa deste artigo foi introduzir ao pesquisador a participação das mulheres na construção dos anais das Histórias em Quadrinhos. O artigo é um estudo inicial de uma ampla pesquisa que acreditamos ser de suma importância, uma vez que são poucos os estudos na área que abrange esse tipo de assunto. Além disso, são inúmeros os livros que contam a biografia das Histórias em Quadrinhos e os nomes das autoras não são apresentados. É como se a mulher não tivesse participado da formação dos pilares das Histórias em Quadrinhos.

Isso é preocupante, pois cria um estereótipo do qual Histórias em Quadrinhos são apenas para meninos, ou que apenas homens trabalham com essa linguagem. Outro equívoco é imaginar que as mulheres não foram pioneiras em técnicas que foram essenciais para as Histórias em Quadrinhos, mesmo após mais de 100 anos de existência se manter como uma linguagem contemporânea e inovadora.

Naturalmente, em um artigo não iremos abranger todas as autoras de Histórias em Quadrinhos, mas entendemos que, para estudos futuros, realizar uma pesquisa mais aprofundada em bibliografias nos ajudará a descobrir autoras que publicaram sob pseudônimos e que são de pouco conhecimento do público. É de se supor que ao realizar um levantamento dessa natureza, iremos reconsiderar a história das Histórias em Quadrinhos a partir do ponto de vista de seus criadores.

É inadmissível que ao estudarmos autores como Danielle Barbieri, Álvaro de Moya entre outros, chegarmos a conclusão que não houve mulheres no processo de desenvolvimento nas Histórias em Quadrinhos, seja na escrita, desenho, linguagem, narrativa, editoração e publicação. Infelizmente foi, a partir dessa experiência de ofício que houve a motivação para a escrita desse referido artigo.

Há, entretanto, diversos motivos que nos fizeram acreditar que nosso estudo não é uma ação isolada. Entendemos que o crescimento de pesquisadoras, autoras e entusiastas com a nona arte, propicia uma confluência de pesquisas que irão resultar no 


\section{midiäticale}

devido reconhecimento dessas autoras, sejam elas pioneiras como Rose O’Neill, inovadoras como Conceição Cahú ou contemporâneas como Kate O’Neill.

Outro fator importante é a sensibilização dos autores e pesquisadores de Histórias em Quadrinhos acerca deste assunto, o que irá fazer com que novas descobertas sejam realizadas e autoras sejam devidamente reconhecidas.

Que fique destacada a importância desse reconhecimento não apenas para os autores, mas para o próprio entendimento da evolução dessa linguagem. Antes de apresentar homens e mulheres estamos apresentando criadores, autores que dedicaram seu processo criativo às Histórias em Quadrinhos. O que não podemos mais aceitar é o estereótipo de que apenas os homens fizeram parte dessa seara de criadores.

\section{Referências}

GROENSTEEN, Thierry. O sistema dos quadrinhos. Nova Iguaçu, RJ: Marsupial Editora, 2015.

JENKINS, Henry; FORD, Sam; GREEN, Joshua. Cultura da Conexão: criando valor e significado por meio da mídia propagável. São Paulo: Aleph, 2014.

GIUSSANI, Angela; GIUSSANI, Luciana. Diabolik. Fumetto publicado em https://www.diabolik.it/non-solo-fumetti-fumetto-on-

line_scheda_larosadeiventi.php?ID=32. Acesso em 2018

HILDE Weber. In: ENCICLOPÉDIA Itaú Cultural de Arte e Cultura Brasileiras. $\begin{array}{llll}\text { São Paulo: } & \text { Itaú } & 2018 .\end{array}$ http://enciclopedia.itaucultural.org.br/pessoa23325/hilde-weber. Acesso em: 15 de Ago. 2018. Verbete da Enciclopédia. ISBN: 978-85-7979-060-7

MAZUR Dan, DANNER Alexander. Quadrinhos - História Moderna de uma Arte Global. São Paulo.WMF Martins Fontes, 2014.

MCCUBBIN, Laurenn. The not-so-secret history of comics drawn by women. Artigo publicado: https:/www.theguardian.com/books/2016/jan/10/women-comics-not-sosecret- history. Acesso em 2018

O’NEILL, Katie. The Tea Dragon Society. Webcomics publicado em https://teadragonsociety.com/ Acesso em 2018 


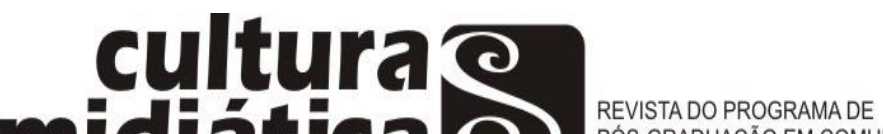 \\ 19.0 (4)}

O’NEILL, Rose. Comic Strip. Arquivo publicado em

http://www.roseoneill.org/mainpage.html. Acesso em 2018

ROBBINS, Trina. Woman in comics - An introductory Guide. Vermont. National Association of Comics Art Educators. Artigo publicado em www.teachingcomics.org. Acesso em 2018.

SOUZA, Worney Almeida de. A cidade e seu Monstro. In: ARMOND, Francisco. Garra Cinzenta. São Paulo: Conrad Editora do Brasil, 2011.

VERGUEIRO, Waldomiro. As Histórias em Quadrinhos no limiar de novos tempos: em busca de sua legitimação como produto artístico e intelectualmente valorizado. In: Visualidades: Revista do Programa de Mestrado em Cultura Visual. Dossiê HQ Vol.07 n.01 Jan/Jun 2009. 